\title{
Evaluation of Thermal Evolution Profiles and Estimation of Kinetic Parameters for Pyrolysis of Coal/Corn Stover Blends Using Thermogravimetric Analysis
}

\author{
Abhijit Bhagavatula, ${ }^{1}$ Gerald Huffman, ${ }^{1}$ Naresh Shah, ${ }^{1}$ and Rick Honaker ${ }^{2}$ \\ ${ }^{1}$ Consortium for Fossil Fuel Science, Department of Chemical and Materials Engineering, University of Kentucky, \\ Lexington, KY 40508, USA \\ ${ }^{2}$ Department of Mining Engineering, University of Kentucky, Lexington, KY 40508, USA
}

Correspondence should be addressed to Abhijit Bhagavatula; abhijitbv@gmail.com

Received 17 October 2013; Revised 31 December 2013; Accepted 11 February 2014; Published 19 March 2014

Academic Editor: Despina Vamvuka

Copyright (C) 2014 Abhijit Bhagavatula et al. This is an open access article distributed under the Creative Commons Attribution License, which permits unrestricted use, distribution, and reproduction in any medium, provided the original work is properly cited.

The thermal evolution profiles and kinetic parameters for the pyrolysis of two Montana coals (DECS-38 subbituminous coal and DECS-25 lignite coal), one biomass sample (corn stover), and their blends (10\%, 20\%, and 30\% by weight of corn stover) have been investigated at a heating rate of $5^{\circ} \mathrm{C} / \mathrm{min}$ in an inert nitrogen atmosphere, using thermogravimetric analysis. The thermal evolution profiles of subbituminous coal and lignite coal display only one major peak over a wide temperature distribution, $\sim 152-814^{\circ} \mathrm{C}$ and $\sim 175-818^{\circ} \mathrm{C}$, respectively, whereas the thermal decomposition profile for corn stover falls in a much narrower band than that of the coals, $\sim 226-608^{\circ} \mathrm{C}$. The nonlinearity in the evolution of volatile matter with increasing percentage of corn stover in the blends verifies the possibility of synergistic behavior in the blends with subbituminous coal where deviations from the predicted yield ranging between $2 \%$ and $7 \%$ were observed whereas very little deviations (1\%-3\%) from predicted yield were observed in blends with lignite indicating no significant interactions with corn stover. In addition, a single first-order reaction model using the CoatsRedfern approximation was utilized to predict the kinetic parameters of the pyrolysis reaction. The kinetic analysis indicated that each thermal evolution profile may be represented as a single first-order reaction. Three temperature regimes were identified for each of the coals while corn stover and the blends were analyzed using two and four temperature regimes, respectively.

\section{Introduction}

The past few years have seen an upsurge in interest in the gasification of biomass for several reasons. They include the following [1].

(1) Reduction in greenhouse gas emissions caused by the combustion of fossil fuels.

(2) A need for energy independence due to the depleting resources and fluctuating prices of oil and natural gas.

(3) Developing interest in renewable energy resources.

Although there is an abundance of coal in the United States and several other countries and the fact that it will continue to be a major source of energy for many years to come, there is still great interest in replacing part of the coal used in energy generation with renewable biomass [2]. Many countries have initiated incentives in recent years to encourage the coutilization of biomass and coal for energy production [3]. The term biomass is used to encompass any plant-derived organic matter available on a renewable basis [2]. Biomass fuels (BF) are to be sustainable natural resources if they renew themselves at such a rate that they will be available for future use, that is, if the rate of consumption of $\mathrm{BF}$ is $\leq$ the rate at which it is generated. These BF resources can be either grown and harvested biomass such as switchgrass or waste biomass such as corn stover, wood wastes from forestry and lumbering operations, wastes from paper production, and landscaping wastes [2]. As is well known, the emission of $\mathrm{CO}_{2}$ during the burning of $\mathrm{BF}$ is neutralized by the removal of $\mathrm{CO}_{2}$ from the 
atmosphere by the process of photosynthesis during biomass growth.

The idea of gasifying mixtures of coal and biomass is relatively new with almost zero commercial experience since the properties of coal and biomass differ significantly from each other [4-7]. Many gasifiers can gasify biomass, but most of them are small scale, operate at lower temperatures and pressures, and use air instead of oxygen. Under these less severe conditions, pyrolysis dominates and produces light hydrocarbons, biooils, tars, and char, in addition to carbon monoxide. Prins et al. [8] reported that fuels with higher oxygen to carbon ratios have larger energy losses due to their high ratio of available chemical energy to heating value. Also, such fuels are overoxidized (combusted) in the gasifier in order to reach the required gasification temperature. Therefore, highly oxygenated fuels are not ideal for gasifiers keeping in view the energy losses that can be incurred and, hence, solid biomass can be more readily gasified if it is cogasified with coal [9].

Pyrolysis or devolatilization (used interchangeably) is the first zone of the gasification process. The chemical components in the raw coal decompose by heating to a relatively low temperature $\left(350-800^{\circ} \mathrm{C}\right)$ in the absence of oxygen. Coal can be considered a complex polymer network consisting of aromatic clusters and aliphatic bridges. During the process of pyrolysis, the complex structure of coal is broken down in to several small fragments whose vapor pressure is high enough to form volatile matter. The duration of evolution of volatiles is relatively shorter for biomass than coal [10]. The products include pyrolysis gases $\left(\mathrm{CO}, \mathrm{H}_{2}, \mathrm{CH}_{4}\right.$, and $\left.\mathrm{H}_{2} \mathrm{O}\right)$, tar, oil, naphtha, and residual solid char $[1,11-13]$. A complete description of the characteristics of pyrolysis is complicated, but, for a given sample, the pyrolysis behavior depends on the heating rate, final decomposition temperature, vapor residence time, the environment under which pyrolysis takes place, pressure, coal particle size, and coal rank [14]. The structure and the composition of the char obtained are also greatly affected by the pyrolysis conditions. This can be considered as the starting point for all heterogeneous gasification reactions.

Kinetic modeling of the devolatilization behavior of coal and biomass is, therefore, an important step in assessing the contribution of single materials and their interactions during the devolatilization stage. The understanding of kinetics of copyrolysis of blends of biomass and coals, particularly the mixtures of Montana coals and corn stover used in this study, is far from clear and, hence, it is important in design and operation of cogasification processes.

Thermogravimetric analysis (TGA) can be used to investigate thermal events and kinetics of pyrolysis and oxidation of the solid raw materials. TGA analysis provides a measurement of weight loss of the sample as a function of time and temperature. The kinetics of the thermal events can then be determined by the application of the Arrhenius equation corresponding to the separate slopes of constant mass degradation in each thermal event with different reaction order, activation energy, and frequency factor. TGA experiments can be carried out either isothermally, where the sample is heated at a constant temperature, or nonisothermally, where the temperature of the sample is increased at a constant rate. Isothermal experiments are typically slower since the sample might take a long time to reach even $50 \%$ conversion at temperatures of $500^{\circ} \mathrm{C}$ or less and multiple experiments are required for determining the kinetic parameters. On the contrary, the kinetic parameters can be determined using only a single experimental run in the nonisothermal mode which can achieve complete conversion in a much shorter period of time [15]. As described earlier, the devolatilization of coalbiomass blends is a complex process and the exact description of the kinetics is not yet available.

\section{Theory}

Several authors have approximated the overall process as a first-order decomposition occurring uniformly throughout the coal and biomass particles [16-23]. For pyrolysis or oxidation reactions under nonisothermal conditions, the heating rate $H$ plays a very important role in determining the kinetic parameters $[15,18,20,23,24]$.

For a first-order reaction at constant heating rate, $H=$ $d T / d t$ :

$$
\frac{d X}{d T}=\left[\frac{A(1-X)}{H}\right] \exp \left(\frac{-E}{R T}\right)
$$

where $A$ is preexponential factor and $E$ is the activation energy.

Integration of the above equation subject to the condition that conversion is zero at initial temperature, $T_{0}$, leads to the following result:

$$
\ln (1-X)=-\left(\frac{A}{H}\right) \int_{T_{0}}^{T} \exp \left(\frac{-E}{R T}\right) d T .
$$

Since there is no conversion at initial temperature, $T_{0}$, the limits of the integral in (2) can be conventionally changed to $\int_{0}^{T} \exp (-E / R T)$, thereby introducing a new function as represented in (3). Consider

$$
f(y)=\int_{y}^{\infty}\left(\frac{e^{-y}}{y^{2}}\right) d y,
$$

where $y=-(E / R T)$.

Therefore, (2) reduces to

$$
\ln (1-X)=-\left(\frac{A}{H}\right) f(y) .
$$

Since (3) cannot be solved analytically, several authors have used different approaches to solve the function $f(y)[20,25-$ 27]. Coats-Redfern approximation [15, 20, 28-30] has been used in this study to determine the approximate value of the temperature integral because of the fact that this method provides the best linearity of the data as opposed to other analytical model-fitting methods $[15,29,30]$. This method is widely used and accepted for the calculation of kinetic parameters. The use of this approximation would help in transforming (3) into simple linear forms and thus obtaining the activation energy, $E$, and preexponential factor, $A$, as 
TABle 1: Proximate and elemental analysis of feedstock.

\begin{tabular}{|c|c|c|c|c|c|c|c|c|c|}
\hline \multirow{2}{*}{ Feedstock } & \multicolumn{4}{|c|}{ Proximate analysis (as-received basis) } & \multicolumn{5}{|c|}{ Elemental analysis (as-received basis) } \\
\hline & \% Moisture & $\%$ Fixed carbon & $\%$ Volatile matter & $\%$ Ash & $\% \mathrm{C}$ & $\% \mathrm{H}$ & $\% \mathrm{~N}$ & $\% \mathrm{~S}$ & $\% \mathrm{O}$ \\
\hline $\begin{array}{l}\text { DECS-38 } \\
\text { subbituminous coal }\end{array}$ & 22.01 & 39.66 & 34.58 & 3.75 & 56.82 & 3.95 & 0.98 & 0.44 & 12.36 \\
\hline DECS-25 lignite coal & 34.91 & 27.32 & 30.05 & 7.71 & 42.80 & 2.99 & 0.61 & 0.47 & 10.50 \\
\hline Corn stover & 5.66 & 10.32 & 76.15 & 7.87 & 42.33 & 6.71 & 0.73 & 0.3 & 42.06 \\
\hline
\end{tabular}

shown in (5) through (7). In this approximation, $f(y)$ is obtained by assuming an asymptotic expansion where only the first two terms are utilized.

Coats-Redfern Approximation. Consider

$$
f(y)=\frac{e^{-y}}{y^{2}}\left[1-\left(\frac{2 !}{y}\right)+\left(\frac{3 !}{y^{2}}\right)-\left(\frac{4 !}{y^{3}}\right)+\cdots\right]
$$

or

$$
f(y) \approx \frac{e^{-y}}{y^{2}}\left(1-\frac{2}{y}\right)
$$

And,

$$
\ln \left[\frac{-\ln (1-X)}{T^{2}}\right]=\ln \left[\left(1-\frac{2 R T}{E}\right) \frac{A R}{H E}\right]-\frac{E}{R T} .
$$

\section{Materials, Experimental Apparatus, and Operation}

The thermal behavior of pure coal, corn stover, and their blends using thermogravimetric analysis would be discussed extensively in this work. The US Department of Energy Coal Samples (DECS) used in this work were obtained from the Pennsylvania State University Coal Sample Database while the corn stover samples were provided by the Center for Applied Energy Research at the University of Kentucky. For the purpose of this work, corn stover (CS) was blended individually up to $30 \%$ by weight with two different ranks of Montana coals, namely, DECS-38 subbituminous coal (SB) and DECS-25 lignite coal (LG) [31]. The samples were crushed and sieved to $150 \mu \mathrm{m}$ before blending to limit the effects of intraparticle heat transfer. The coal-corn stover blends were prepared in appropriate proportions and homogenized by constant stirring in the sample holders to ensure sufficient dispersion. Subsequently, their nonisothermal weight loss profiles were evaluated and copyrolysis kinetic parameters were determined using the integral method as described in Section 2. Montana coals were chosen based on economic considerations, their low sulfur content, and high percentage of carbon present since the ultimate goal is to gasify these blends in a moving bed reactor for the production of syngas that can be used as feedstock for downstream processes such as the Fischer-Tropsch synthesis used for producing liquid fuels. Also, keeping in view the overall gasification process, blends of higher percentages of biomass (in excess of $30 \%$ by weight) were not possible for the conditions at which the gasifier was operated since biomass is a low density, low heating value fuel and addition of more biomass would make the gasification process less efficient. Hence, a maximum of $30 \%$ by weight of biomass was chosen for this study. The proximate and elemental analyses of the single fuels are presented in Table 1. Proximate analysis of the feedstock samples was conducted according to ASTM standard D7582-12 [32] using a Netzsch Jupiter STA 449 Simultaneous Thermal Analyzer. The percentages of $\mathrm{C}, \mathrm{H}$, and $\mathrm{N}$ in the feedstock samples were determined according to ASTM standard D5373-08 [33] using a LECO 628 Series Carbon/Hydrogen/Nitrogen Analyzer comprising of a dual-stage furnace operating at $1050^{\circ} \mathrm{C}$ while the percentage of sulfur in the sample was determined according to ASTM standard D4239-12 [34] using LECO SC 632 Carbon and Sulfur Analyzer and oxygen percentage obtained by difference.

As a part of this, pyrolysis of the different types of feedstock was carried out in nonisothermal mode using a TA-SDT-Q600 thermogravimetric analyzer. The weight of the samples used for these experiments was about $40 \mathrm{mg}$ for the coal samples and about $10 \mathrm{mg}$ for the corn stover samples on an as-received basis (which is approximately $25 \mathrm{mg}$ for coal samples and $8 \mathrm{mg}$ for corn stover on a dry basis). Pure nitrogen was used as the purge gas. Flow of pure nitrogen through the system negates sample oxidation and also removes the volatile pyrolysis products, thus ensuring an inert atmosphere during the run. In the nonisothermal mode, once the sample is inserted into the furnace, the temperature of the furnace was increased from room temperature to $127^{\circ} \mathrm{C}$ and held at that temperature for 15 minutes to ensure drying. Subsequently, the furnace temperature was raised to $900^{\circ} \mathrm{C}$ at a constant heating rate of $5^{\circ} \mathrm{C} / \mathrm{min}$. An inert nitrogen atmosphere was employed throughout the process and the nitrogen flow rate was maintained constant at $100 \mathrm{~mL} / \mathrm{min}$. Upon reaching a temperature of $900^{\circ} \mathrm{C}$, air was introduced into the furnace to burn off the remaining char and obtain the percentage of ash in the respective samples. Also, the heat transfer limitations may be ignored due to the fact that the furnace heats up slowly combined with a low weight of the sample being pyrolyzed. The process was repeated four times to ensure reproducibility of the weight loss profiles for each sample (error $<5 \%$ for all samples).

\section{Results and Discussion}

4.1. Thermal Evolution Profiles. The weight loss curves (dry ash free basis) during the nonisothermal pyrolysis at a heating rate of $5^{\circ} \mathrm{C} / \mathrm{min}$ for all the feedstock being discussed in this work are shown in Figures 1(a) and 1(b). 


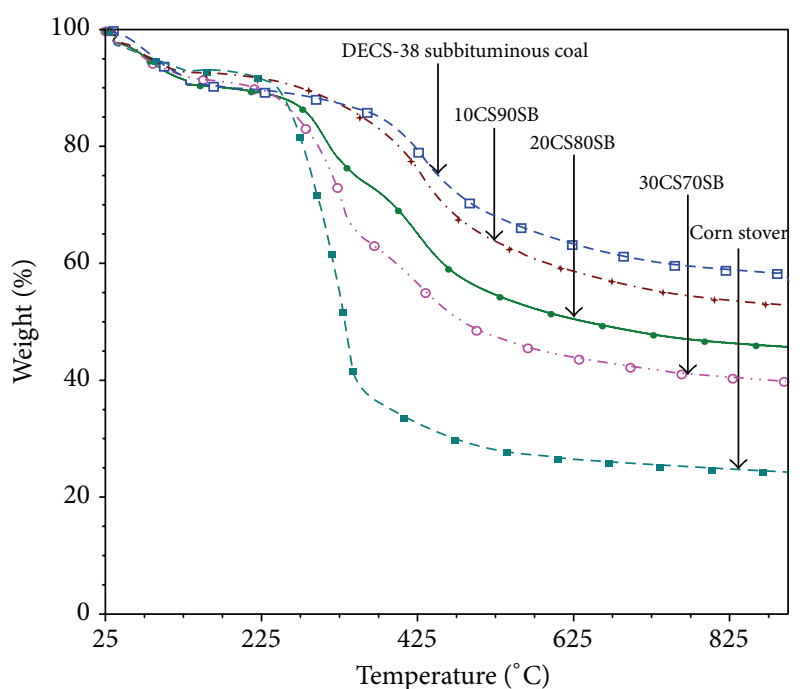

(a)

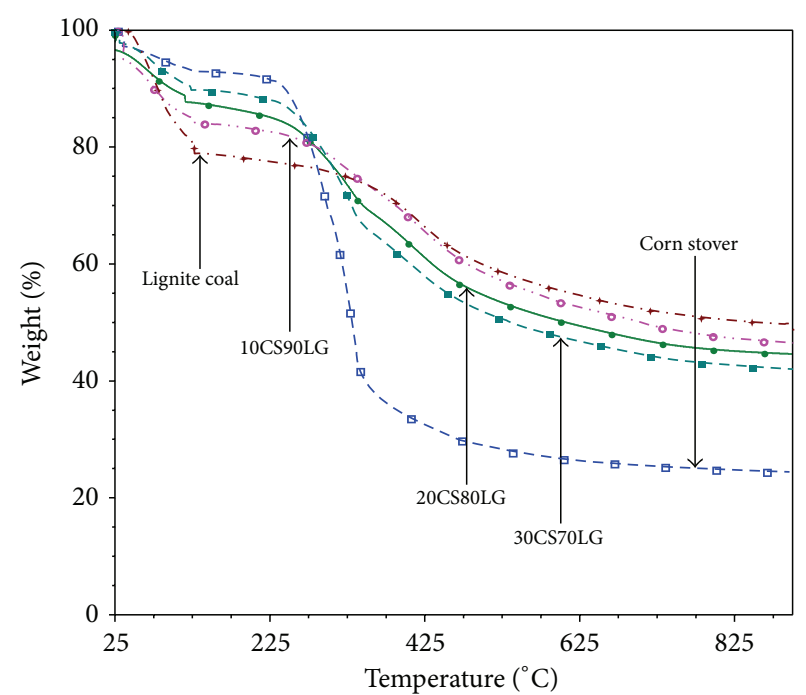

(b)

Figure 1: (a) Weight loss curves during the pyrolysis of DECS-38 subbituminous coal, corn stover, and their blends at $5^{\circ} \mathrm{C} / \mathrm{min}$. (b) Weight loss curves during the pyrolysis of DECS-25 lignite coal, corn stover, and their blends at $5^{\circ} \mathrm{C} / \mathrm{min}$.

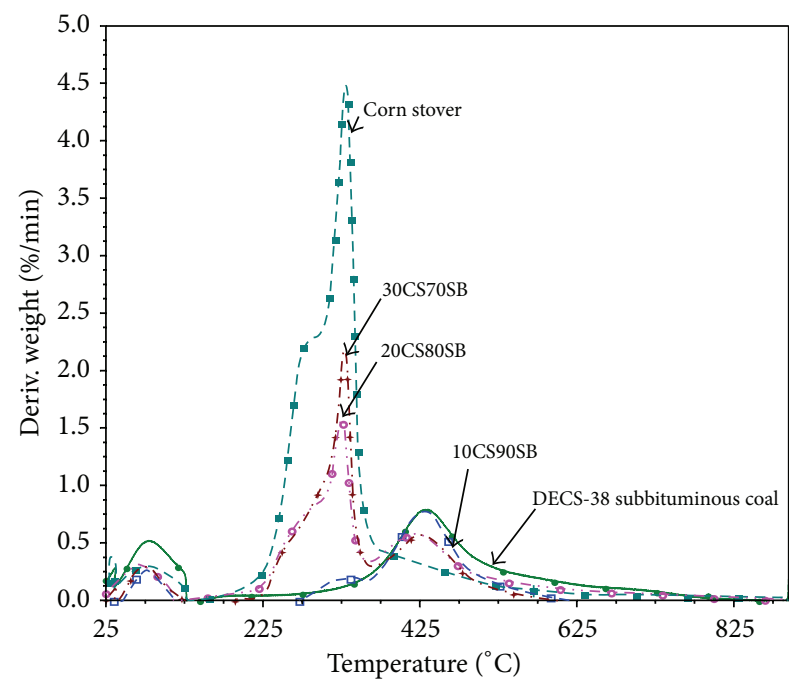

(a)

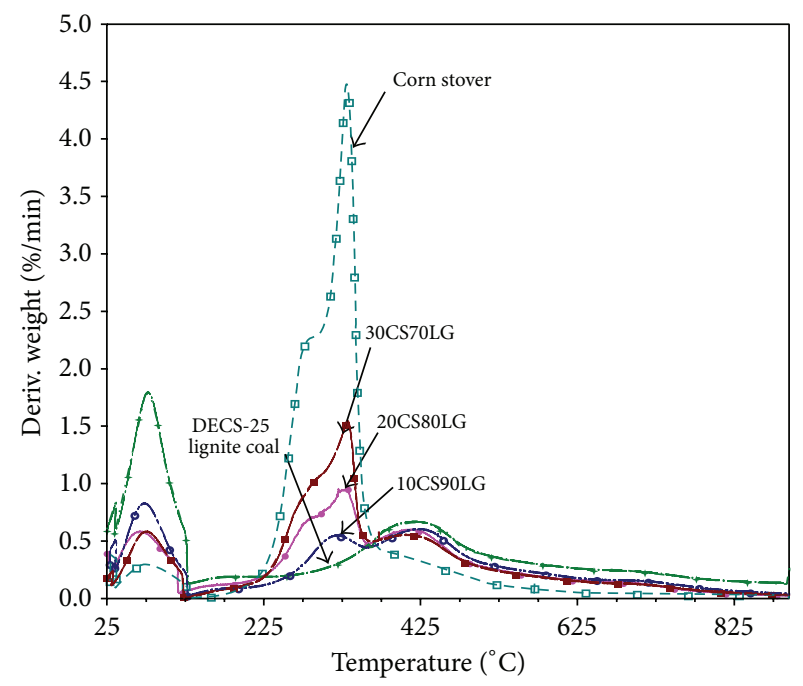

(b)

FIGURE 2: (a) Differential thermogravimetric curves of pyrolysis of SB-CS blends at $5^{\circ} \mathrm{C} / \mathrm{min}$. (b) Differential thermogravimetric curves of pyrolysis of LG-CS blends at $5^{\circ} \mathrm{C} / \mathrm{min}$.

The weight loss increases with increasing reaction temperature for all samples. Also, the weight loss profiles of the coal-biomass blends fall between those of the isolated single fuels. Figures 2(a) and 2(b) depict the differential thermogravimetric (DTG) curves of the samples used in this work, as a function of pyrolysis temperature, at a heating rate of $5^{\circ} \mathrm{C} / \mathrm{min}$. It can be seen that the samples display one peak at temperatures less than $150^{\circ} \mathrm{C}$ representing the removal of moisture from the samples [35]. Above this temperature, varied peaks are observed for the coals, corn stover, and their blends. Table 2 summarizes some of the pyrolysis parameters, such as, pyrolysis temperature range $\left(T_{i}\right.$ is the temperature of initial weight loss and $T_{f}$ is the temperature at the end of the reaction), maximum weight loss rates, and corresponding maximum DTG peak temperatures.

The thermal evolution profiles of DECS-38 subbituminous coal (SB) and DECS-25 lignite coal (LG) display only one major peak over a wide temperature distribution, $\sim 152-$ $814^{\circ} \mathrm{C}$ for $\mathrm{SB}$ and $\sim 175-818^{\circ} \mathrm{C}$ for LG. This peak represents the release of carbon containing volatile matter from both coals [35]. The maximum peak temperature for this major peak is approximately $433^{\circ} \mathrm{C}$ and $419^{\circ} \mathrm{C}$, respectively, for SB and LG. It is worth noting that the maximum weight loss rate of LG is much lower than that of SB. This can attributed to the fact 
TABLE 2: Pyrolysis temperature range, maximum weight loss rates, and peak temperatures of all types of feedstock determined by TGA.

\begin{tabular}{|c|c|c|c|c|c|c|}
\hline \multirow{2}{*}{ Feedstock materials } & \multicolumn{2}{|c|}{ Pyrolysis $T$ range, ${ }^{\circ} \mathrm{C}$} & \multicolumn{2}{|c|}{ Maximum weight loss rate, $(\% / \mathrm{min})_{\max }$} & \multicolumn{2}{|c|}{ Peak temperature, $T_{\max },{ }^{\circ} \mathrm{C}$} \\
\hline & $T_{i}$ & $T_{f}$ & Peak $1(\mathrm{CS})$ & Peak 2 (Coal) & $T_{\max , 1}$ & $T_{\max , 2}$ \\
\hline DECS-38 subbituminous coal & 152 & 814 & - & 0.889 & - & 433 \\
\hline DECS-25 lignite coal (LG) & 175 & 818 & - & 0.668 & - & 419 \\
\hline Corn stover (CS) & 226 & 608 & 4.492 & - & 331 & - \\
\hline $10 \% \mathrm{CS}+90 \% \mathrm{SB}$ & 207 & 787 & 0.251 & 0.819 & 330 & 430 \\
\hline $20 \% \mathrm{CS}+80 \% \mathrm{SB}$ & 204 & 765 & 1.492 & 0.500 & 326 & 419 \\
\hline $30 \% \mathrm{CS}+70 \% \mathrm{SB}$ & 190 & 755 & 2.332 & 0.561 & 330 & 427 \\
\hline $10 \% \mathrm{CS}+90 \% \mathrm{LG}$ & 176 & 815 & 0.550 & 0.603 & 318 & 423 \\
\hline $20 \% \mathrm{CS}+80 \% \mathrm{LG}$ & 201 & 785 & 0.941 & 0.599 & 327 & 411 \\
\hline $30 \% \mathrm{CS}+70 \% \mathrm{LG}$ & 199 & 755 & 1.550 & 0.552 & 336 & 413 \\
\hline
\end{tabular}

that LG contains much lower content of volatile matter than $\mathrm{SB}$ as shown in Table 1 .

Also, the maximum weight loss rates for the coals occur in a temperature range of $400-500^{\circ} \mathrm{C}$ corresponding to the data reported by Sun et al. [36]. In the case of corn stover (CS), the thermal evolution profile can be divided into three more stages apart from moisture removal corresponding to the removal of hemicellulose, cellulose, and lignin components of corn stover. The decomposition of the hemicellulose and cellulose components of corn stover can also be termed as the active pyrolysis zone while the slow decomposition of the lignin component represents the passive pyrolysis zone. This is generally the case for all lignocellulosic materials [37]. As it can be seen, the thermal decomposition profile for CS falls in a much narrower band than that of the coals, $226-608^{\circ} \mathrm{C}$. This is mainly due to the high volatile content and lower fixed carbon content of CS as compared with that of the coals.

This difference is also attributed to the strength of the molecular structure of the fuels. The immobile phase present in coal structure comprises dense polycyclic aromatic hydrocarbons linked together by aromatic rings with very high bond energy of about $1000 \mathrm{~kJ} / \mathrm{mol}$ [18]. In contrast, the polymers of hemicellulose, cellulose, and lignin which constitute the macromolecular structure of biomass and other woody materials are linked together by relatively weak bonds with a bond energy of about $380-420 \mathrm{~kJ} / \mathrm{mol}$ [38]. These bonds are less resistant to heat at low temperatures. As a consequence, a much higher mass loss rate results in biomass samples as compared with coal as can be seen from Table 2. The maximum weight loss rate of CS is almost an order of magnitude higher than both coals. As observed, the DTG profile of CS results in a split peak in the temperature range of $\sim 226-375^{\circ} \mathrm{C}$. The lower temperature shoulder represents the decomposition of the hemicellulose component with a peak temperature of $\sim 286^{\circ} \mathrm{C}$ and a weight loss rate of $2.278 \% / \mathrm{min}$ while the higher temperature peak represents the decomposition of the cellulose component with a maximum weight loss rate of $4.492 \% / \mathrm{min}$ at a temperature of $331^{\circ} \mathrm{C}$. This decomposition continues up to a temperature of approximately $375^{\circ} \mathrm{C}$. Above this temperature, the slow decomposition of the lignin component begins continuing

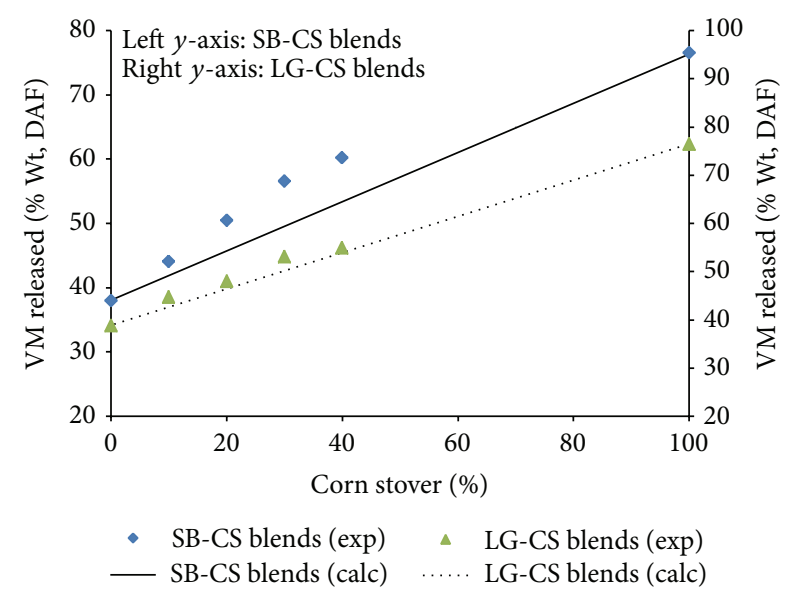

FIGURE 3: Disparity in the experimental and predicted curves during the release of volatile matter with increasing concentration of biomass.

up to a temperature of about $608^{\circ} \mathrm{C}$ beyond which very little change in the weight occurs.

As for the blends of both coals with corn stover, the DTG curves are represented in Figure 3. The DTG evolution profiles for different blends of CS with SB and LG showed two distinct peaks in the temperature range of approximately 176$815^{\circ} \mathrm{C}$. For blends of CS and SB, the first peak occurs at a maximum peak temperature of approximately $326-330^{\circ} \mathrm{C}$ representing the devolatilization of CS (evolution of hemicellulose and cellulose components) while the second peak occurs at a maximum peak temperature of $419-430^{\circ} \mathrm{C}$ representing the devolatilization of SB. Similar trends are observed for blends of CS and LG with maximum peak temperatures ranging from 318 to $336^{\circ} \mathrm{C}$ for the devolatilization of CS and from 411 to $423^{\circ} \mathrm{C}$ for the devolatilization of LG. Also, it can be observed that the maximum weight loss rate $(\% / \mathrm{min})$ for the CS devolatilization profile increased with increasing concentration of CS in the blends and vice versa for the coal devolatilization profile, without an apparent change in the shape and position of the peaks when compared to those of the single fuels. This may be attributed to the fact that 


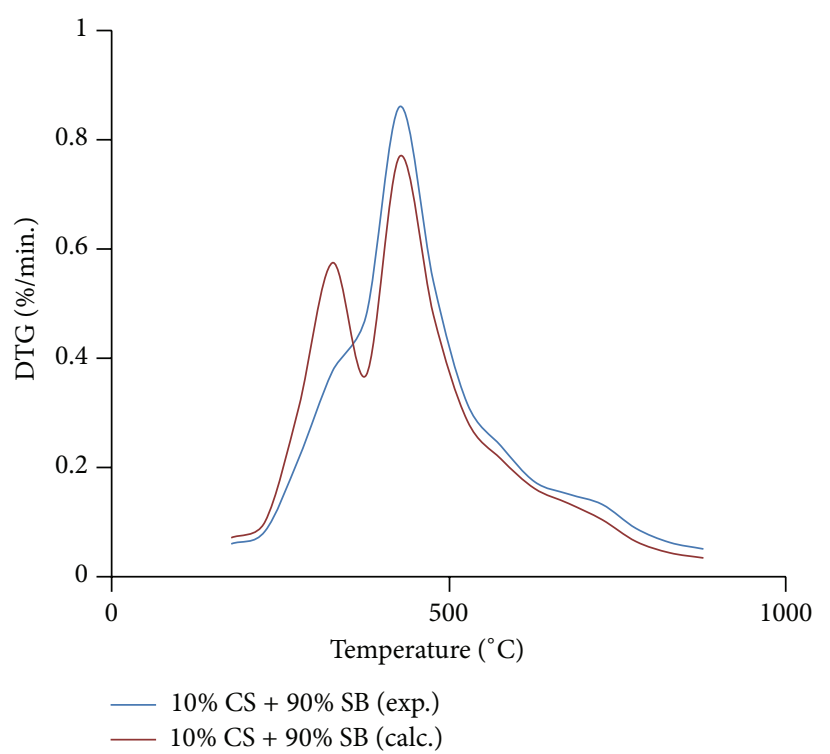

(a)

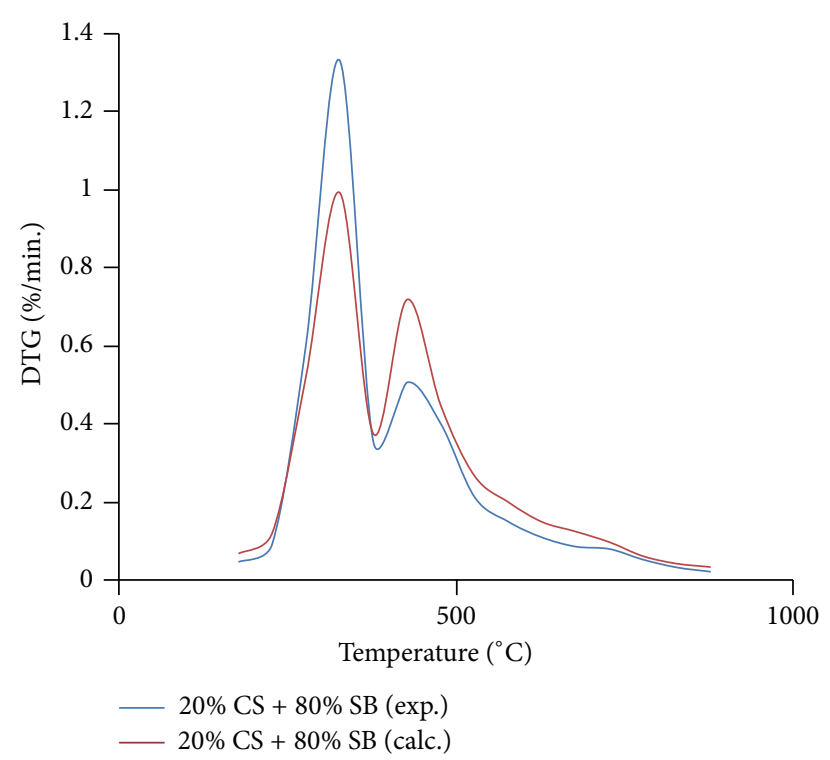

(b)

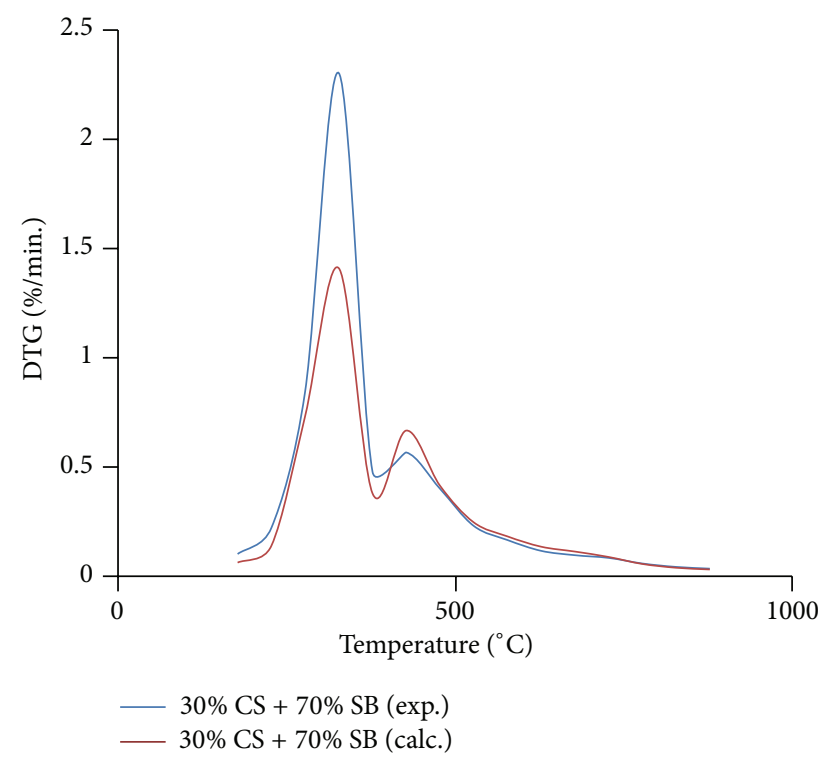

(c)

FIGURE 4: Comparison of the experimental and predicted DTG curves for (a) $10 \%$ CS $+90 \%$ SB blend, (b) $20 \%$ CS $+80 \%$ SB blend, and (c) $30 \%$ CS $+70 \%$ SB blend.

the release of volatiles containing oxygenated components during the devolatilization of CS, generally, does not affect the devolatilization of coal at higher temperatures $[35,39,40]$. But, it must be noted here that the change in the maximum devolatilization rate is not linear with the increase in corn stover percentage indicating the possibility of interactions between the blended fuels.

4.2. Analysis of Synergistic Interactions in Blends. In order to investigate the synergistic behavior between the coals and corn stover in the blends, the disparity in the amount of volatile matter released was evaluated between the experimental and calculated curves as shown in Figure 3. In order to better analyze the synergistic behavior between the blended fuels, an additional experimental run consisting of $40 \%$ corn stover was also performed. The predicted amount of volatile matter released was calculated using a simple additive relationship [41, 42] as shown in (8). Consider

$$
\mathrm{VM}_{\text {Calc, Blend }}=X_{\text {Coal }} * \mathrm{VM}_{\text {Coal, Obs }}+X_{\mathrm{CS}} * \mathrm{VM}_{\mathrm{CS}, \mathrm{Obs}},
$$

where $X_{i}$ refers to the fraction of each material in the blend and $\mathrm{VM}$ is the $\%$ of volatile matter evolved.

For the TGA experimental runs performed, the percentage of volatile matter evolved increases with an increase in the percentage of corn stover in the blend which is an expected 


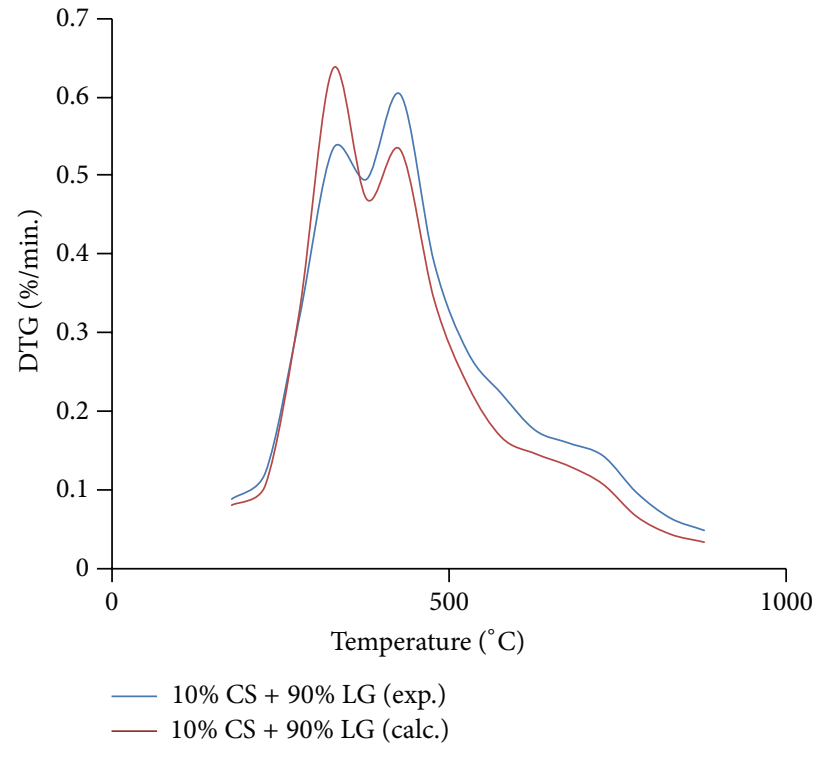

(a)

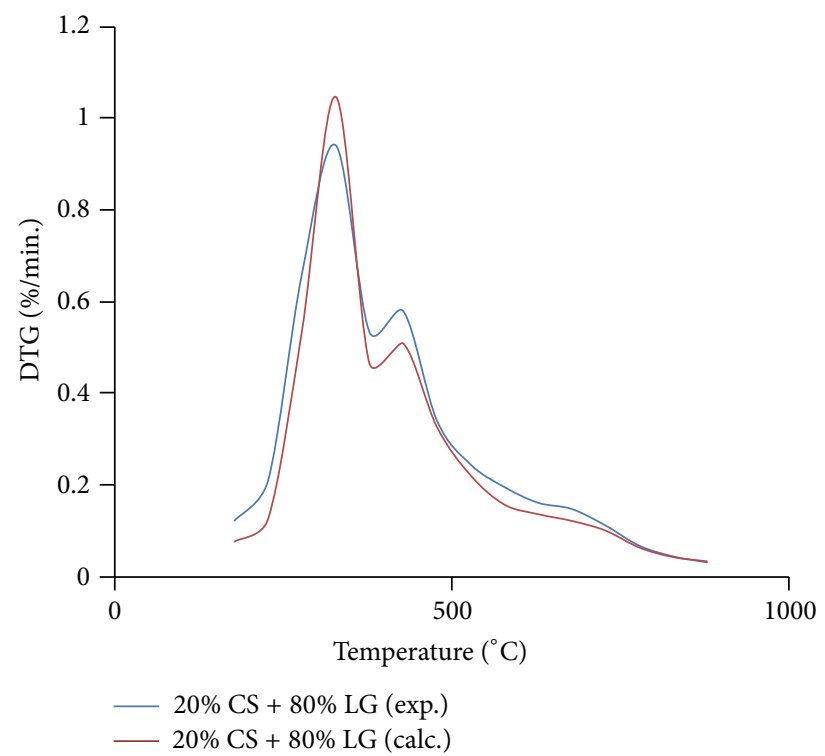

(b)

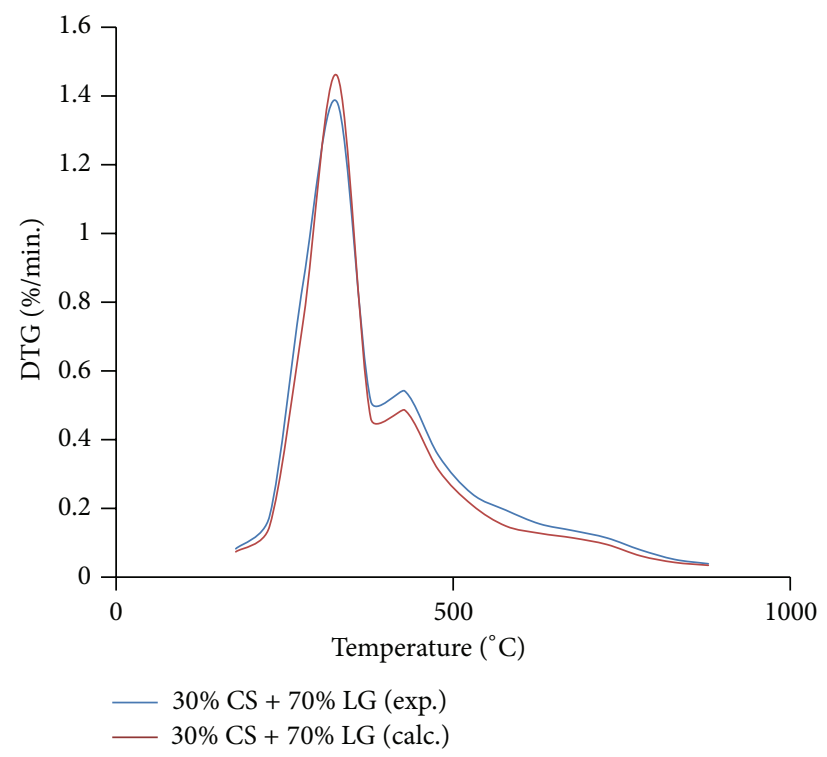

(c)

Figure 5: Comparison of the experimental and predicted DTG curves for (a) 10\% CS + 90\% LG blend, (b) $20 \%$ CS + 80\% LG blend, and (c) $30 \%$ CS $+70 \%$ LG blend.

result due to the fact that corn stover has higher volatile content inherently.

However, it is noteworthy that this increase in volatile matter with increasing corn stover concentration in the blends of corn stover with subbituminous coal is not linear with deviations from the predicted yield ranging between $2 \%$ and $7 \%$, indicating some kind of synergistic behavior between the blended materials unlike some previous works indicated in the literature $[38,43]$. On the contrary, for blends of corn stover with lignite, the deviations from the predicted yield are much lower (1\%-3\%), implying very little synergistic interactions between corn stover and lignite.
In order to further verify this assumption and delve deeper into the synergistic behavior between the materials, the calculated and experimental DTG curves were plotted as shown in Figures 4 and 5. The calculated DTG curves were estimated using an equation similar to (8) by replacing the $\%$ of volatile matter evolved with the weight loss rate of the material. The DTG curves for SB and CS blends show that the predicted and experimental curves match closely at temperatures above $500^{\circ} \mathrm{C}$ indicating that synergy between the materials exists at lower temperatures $\left(\sim 230-450^{\circ} \mathrm{C}\right)$. Also, increasing the percentage of CS in the blend lowers the temperature $\left(\sim 380^{\circ} \mathrm{C}\right)$ until when synergistic behavior is observed. In the case of CS and LG blends, the disparity in the 


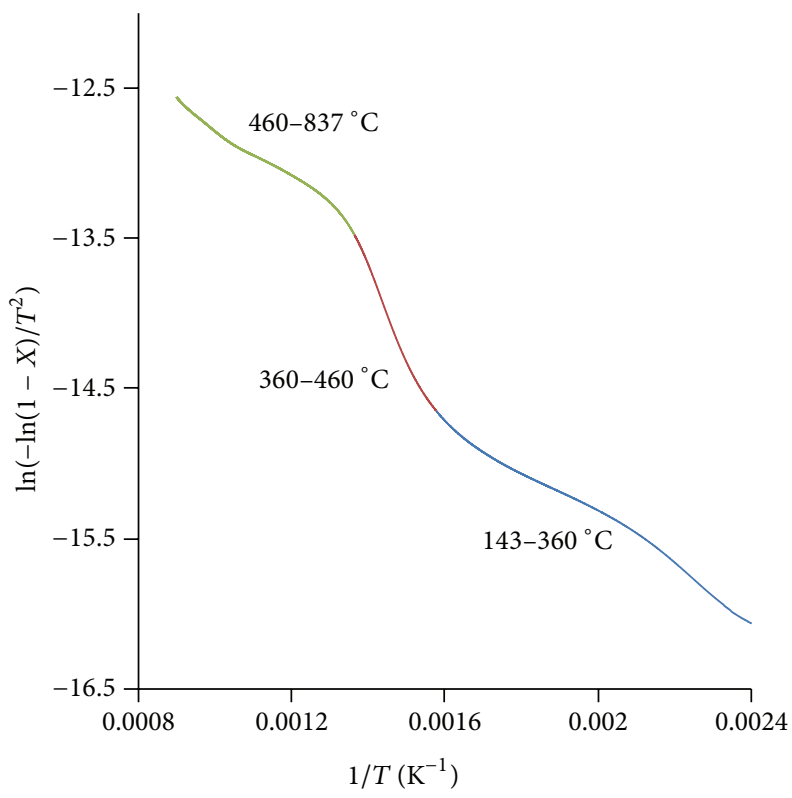

(a)

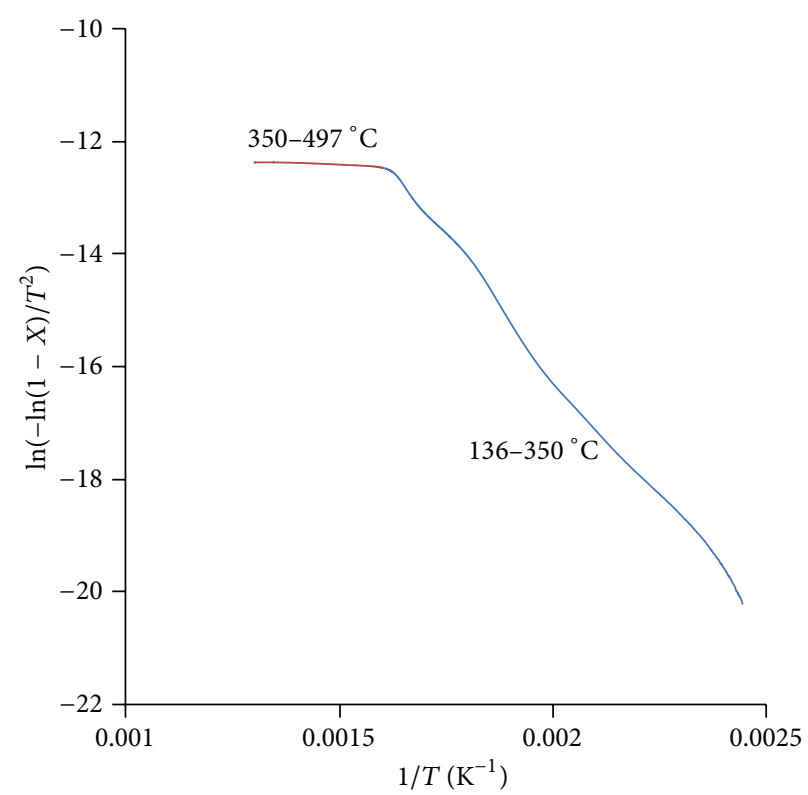

(b)

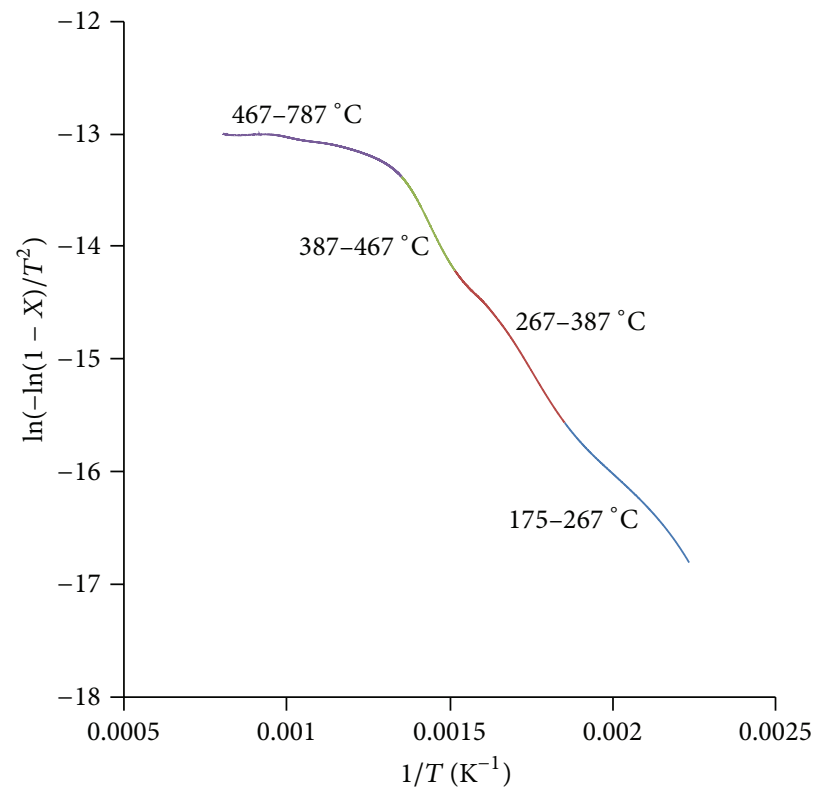

(c)

FIGURE 6: Analysis of the thermal evolution profiles and temperature ranges for pyrolysis of (a) DECS-38 subbituminous coal, (b) corn stover, and (c) $10 \%$ CS and $90 \%$ SB blend.

predicted and experimental DTG curves is quite apparent at lower concentrations of CS. The synergistic behavior for $10 \%$ CS and $90 \%$ LG starts at about $320^{\circ} \mathrm{C}$ continuing until the end of pyrolysis. However, increasing the CS percentage to $30 \%$ drastically reduces the synergistic behavior. This can be observed only at higher temperatures $\left(\sim 380-680^{\circ} \mathrm{C}\right)$, albeit, with very less deviations in both curves.

4.3. Kinetic Analysis. As described in (1) through (7), using Coats-Redfern approximation, the kinetic parameters, activation energy, and preexponential factor were determined for both single fuels and the blends. From the pyrolysis data obtained, it is evident that different constituents of the sample pyrolyze at different temperatures and each temperature regime may be represented with a specific set of kinetic parameters. Each zone or temperature regime was estimated through inflection points or tangents drawn along the weight loss curves once moisture has been removed. The points corresponding to the tangents were marked as the beginning of a particular temperature zone of the total pyrolysis regime. Figure 6 shows the first-order plot of $\ln \left[-\ln (1-X) / T^{2}\right]$ versus $1 / T$. As described in Section 2, the activation energy can be 


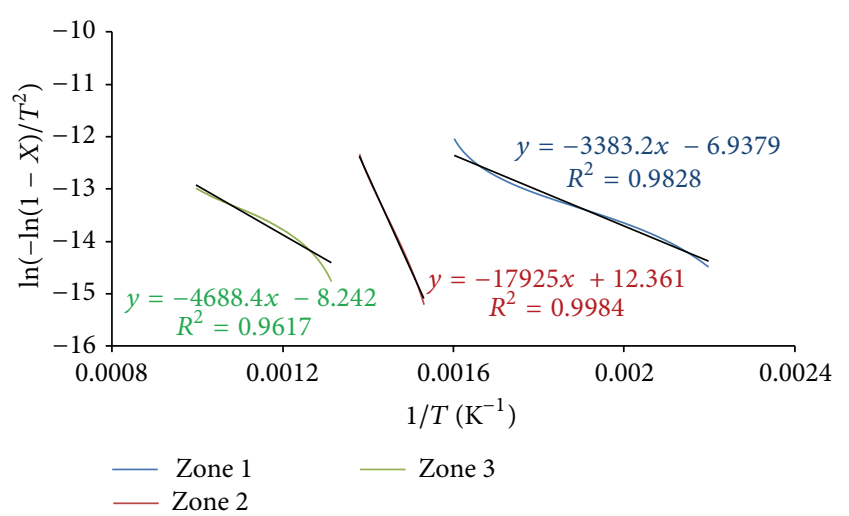

(a)

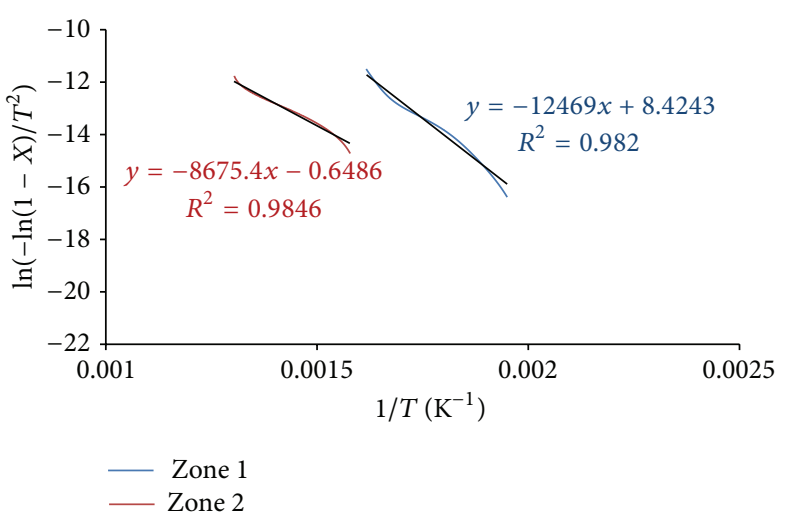

(b)

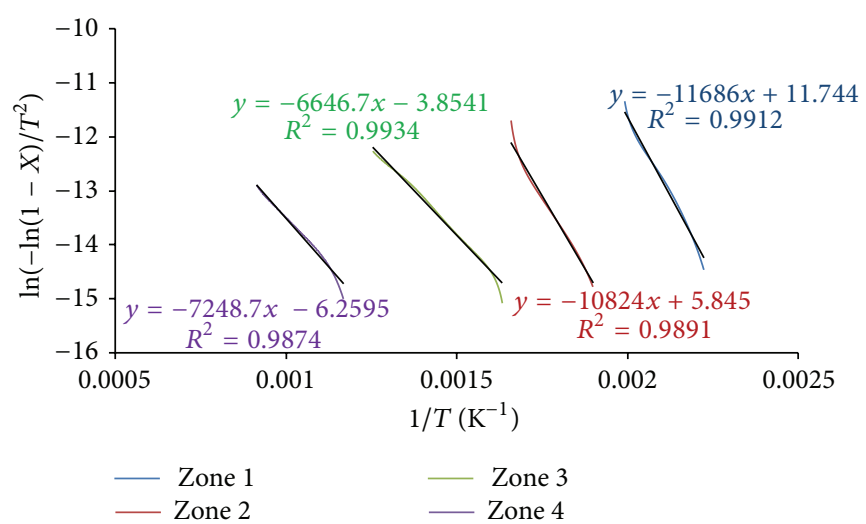

(c)

FIGURE 7: Estimation of kinetic parameters for pyrolysis of (a) DECS-38 subbituminous coal, (b) corn stover, and (c) $10 \%$ CS and $90 \%$ SB blend.

estimated from the slope of this plot while the preexponential factor can be estimated from the intercept by taking the temperature at which $W_{t}=\left(W_{0}+W_{f}\right) / 2$.

The pyrolysis of subbituminous coal may be described as a process with three consecutive first-order reactions. In order to apply (7), the conversion was recalculated for each zone separately to determine the kinetic parameters for the respective zones. A similar procedure was carried out for estimating the kinetic parameters of DECS-25 lignite coal and blends of both coals with corn stover. Lignite coal also has three zones where the first-order analysis can be applied while the corn stover has two independent zones and the blends contain at least four different zones. As an illustration, Figure 7 depicts the kinetic analysis for the pyrolysis of DECS-38 subbituminous coal, corn stover, and 10\% CS and $90 \%$ SB blend.

Thus, the coal devolatilization process can be divided into three stages $[18,23,38]$. For DECS-38 subbituminous coal, in the first stage, for temperatures less than $360^{\circ} \mathrm{C}$ or until a conversion level of approximately $16 \%$, only the peripheral parts and the mobile phase of the macromolecular structure of coal decompose. This zone will have relatively lower activation energy as shown in Table 3 . In the second stage, for temperatures between $360^{\circ} \mathrm{C}$ and $460^{\circ} \mathrm{C}$ (conversion between $16 \%$ and $53 \%$ ), pyrolysis liquids and gases are the main products. As explained earlier, this zone mainly comprises the immobile phase of the coal structure which is more resistant to heat. Therefore, only a small amount of fragmented polycyclic aromatic compounds are produced during this phase. Hence, the activation energy of this phase is much higher than that of the first phase. In the last stage, for temperatures greater than $460^{\circ} \mathrm{C}$, the remaining macromolecular structure of coal is further decomposed. The activation energy in this case is much lower than that of the second phase indicating that during the third stage, repolymerization or crosslinking reaction resulting in the formation of char as the pyrolysis product occurs more easily since most of the volatiles or oxygen containing functional groups have been removed in the previous stages. Apart from this, it can be seen that the kinetic zones for the coalbiomass blend are slightly different from those of coals. For coal-biomass blends, four independent reactions are used to describe the copyrolysis process. It can be noted that the conversion range for the first stage is only up to $\sim 7 \%$ indicating that the main decomposition of the coal-biomass blend occurs at higher temperatures. As seen from Table 3, the kinetic parameters for the different thermal evolution profiles during the copyrolysis of coal and corn stover blends have been predicted. The good correlation factor indicates that each thermal evolution profile may be represented as a single first-order reaction. 
TABLE 3: Obtained pyrolysis kinetic parameters, temperature, and conversion ranges for all types of feedstock at a heating rate of $5^{\circ} \mathrm{C} / \mathrm{min}$.

\begin{tabular}{|c|c|c|c|c|c|}
\hline Feedstock materials & $\begin{array}{c}\text { Temperature } \\
{ }^{\circ} \mathrm{C}\end{array}$ & $\begin{array}{c}\text { Conversion } \\
\text { range, } \%\end{array}$ & $\begin{array}{c}\text { Activation } \\
\text { energy } E \text {, } \\
\mathrm{KJ} / \mathrm{mol}\end{array}$ & $\begin{array}{c}\text { Arrhenius } \\
\text { constant, } \\
\min ^{-1}\end{array}$ & $\begin{array}{c}\text { Correlation } \\
\text { coefficient, } R^{2}\end{array}$ \\
\hline \multirow{3}{*}{ DECS-38 subbituminous coal (SB) } & $143-360$ & $2-16$ & 28.13 & $2.46 E+01$ & 0.9828 \\
\hline & $360-460$ & $16-53$ & 149.03 & $2.27 E+10$ & 0.9984 \\
\hline & $460-837$ & $53-98$ & 38.98 & $9.55 E+00$ & 0.9616 \\
\hline \multirow{3}{*}{ DECS-25 lignite coal (LG) } & $175-281$ & $2-9$ & 56.96 & $8.37 E+04$ & 0.9973 \\
\hline & $281-457$ & $9-55$ & 78.15 & $1.13 E+05$ & 0.9948 \\
\hline & $457-791$ & $55-97$ & 41.75 & $1.40 E+01$ & 0.9909 \\
\hline \multirow{2}{*}{ Corn stover (CS) } & $136-350$ & $3-77$ & 103.67 & $3.13 E+08$ & 0.9820 \\
\hline & $350-497$ & $77-92$ & 72.13 & $2.69 E+04$ & 0.9846 \\
\hline \multirow{4}{*}{$10 \% \mathrm{CS}+90 \% \mathrm{SB}$} & $175-267$ & $1-5$ & 67.90 & $1.36 E+06$ & 0.9886 \\
\hline & $267-387$ & $5-25$ & 82.47 & $1.20 E+06$ & 0.9907 \\
\hline & $387-467$ & $25-57$ & 179.16 & $3.37 E+12$ & 0.9905 \\
\hline & $467-787$ & $57-97$ & 25.69 & $1.18 E+00$ & 0.9785 \\
\hline \multirow{4}{*}{$20 \% \mathrm{CS}+80 \% \mathrm{SB}$} & $150-244$ & $1-5$ & 57.39 & $1.92 E+05$ & 0.9984 \\
\hline & $244-360$ & $5-38$ & 107.69 & $6.30 E+08$ & 0.9893 \\
\hline & $360-496$ & $38-75$ & 107.07 & $9.69 E+06$ & 0.9913 \\
\hline & 496-843 & $75-97$ & 45.85 & $1.88 E+01$ & 0.9814 \\
\hline \multirow{4}{*}{$30 \% \mathrm{CS}+70 \% \mathrm{SB}$} & $166-231$ & $1-5$ & 97.16 & $8.02 E+09$ & 0.9912 \\
\hline & $231-332$ & $5-43$ & 89.99 & $2.09 E+07$ & 0.9891 \\
\hline & $332-550$ & $43-86$ & 55.26 & $8.89 E+02$ & 0.9934 \\
\hline & 550-854 & 86-97 & 60.27 & $9.31 E+01$ & 0.9874 \\
\hline \multirow{4}{*}{$10 \% \mathrm{CS}+90 \% \mathrm{LG}$} & $156-265$ & $1-7$ & 53.61 & $9.52 E+04$ & 0.9915 \\
\hline & $265-338$ & $7-22$ & 138.82 & $9.92 E+11$ & 0.9967 \\
\hline & $338-451$ & $20-53$ & 100.42 & $1.29 E+07$ & 0.9921 \\
\hline & $451-853$ & $53-98$ & 28.71 & $3.63 E+00$ & 0.9895 \\
\hline \multirow{4}{*}{$20 \% \mathrm{CS}+80 \% \mathrm{LG}$} & $156-224$ & $2-6$ & 64.59 & $2.69 E+06$ & 0.9905 \\
\hline & $224-308$ & $6-18$ & 126.01 & $2.06 E+11$ & 0.9927 \\
\hline & $308-437$ & $18-61$ & 96.90 & $3.02+03$ & 0.9892 \\
\hline & 437-835 & $61-97$ & 30.37 & $1.53 E+00$ & 0.9872 \\
\hline \multirow{4}{*}{$30 \% \mathrm{CS}+70 \% \mathrm{LG}$} & $171-245$ & $1-5$ & 87.10 & $2.85 E+08$ & 0.9889 \\
\hline & $245-342$ & $5-45$ & 99.15 & $1.22 E+08$ & 0.9933 \\
\hline & $342-455$ & $45-71$ & 93.14 & $1.81 E+06$ & 0.9888 \\
\hline & $455-880$ & 71-98 & 34.98 & $4.53 E+00$ & 0.9790 \\
\hline
\end{tabular}

\section{Conclusions}

Thermogravimetric analysis has been performed on nine feed materials, that is, three single fuels and four blends, and the pyrolysis characteristics were analyzed. The kinetic parameters were determined for the pyrolysis reaction using a nonisothermal mode of operation and single first-order reaction model at a heating rate of $5^{\circ} \mathrm{C} / \mathrm{min}$.

The lower final weight loss of subbituminous coal is related to the high content of fixed carbon which is not decomposed in this temperature range. Also, it can be observed that corn stover has the highest weight loss percentage. This trend is due to the high volatile content and low fixed carbon content in corn stover as compared to coals. Also, the pyrolysis temperature range decreased with an increase in the concentration of corn stover in the blends due to the fact that corn stover has a much higher weight loss rate when compared to that of the coals.

The pyrolysis of both subbituminous and lignite coals can be reasonably described as a process with three consecutive first-order reactions with distinct temperature zones while corn stover and the blends have two and four distinct temperature zones, respectively, where the first-order kinetic analysis can be applied. Also, it was observed that the second thermal event during the coal pyrolysis has the highest activation energy of $\sim 149 \mathrm{KJ} / \mathrm{mol}$ for DECS-38 subbituminous coal and $\sim 78 \mathrm{KJ} / \mathrm{mol}$ for DECS-25 lignite coal. As for corn stover, the major pyrolysis region is in the temperature range of $136-350^{\circ} \mathrm{C}$ where a majority $(\sim 77 \%)$ of the mass fraction is removed with an activation energy of $\sim 104 \mathrm{KJ} / \mathrm{mol}$. It can 
also be seen that the activation energies of the blends are not simply additive in nature further indicating a possibility of interactions between the individual fuels. Apart from this, a thorough investigation into the synergistic behavior between single fuels in the blends has been performed with the conclusion that there are definite interactions between the DECS38 subbituminous coal and corn stover in the temperature range of $230-450^{\circ} \mathrm{C}$. But, in the case of blends of DECS-25 lignite coal and corn stover, minimal synergistic behavior was observed only at lower concentrations of corn stover starting at a temperature of about $320^{\circ} \mathrm{C}$. Finally, the kinetic analysis described in this work may only be used as a starting point for developing more complex and predictive models for accurately estimating the copyrolysis behavior of different biomass materials and coals.

\section{Conflict of Interests}

The authors declare that there is no conflict of interests regarding the publication of this paper.

\section{Acknowledgments}

The authors would like to express their gratitude to the Department of Energy for funding this research and also to Dr. Darrell Taulbee at the Center for Applied Energy Research at University of Kentucky for the timely support in providing the samples of corn stover and chemical analyses of the feedstock samples.

\section{References}

[1] P. Basu, Biomass Gasification and Pyrolysis: Practical Design and Theory, Elsevier, New York, NY, USA, 2010.

[2] R. C. Brown, Biorenewable Resources: Engineering New Products from Agriculture, Blackwell Publishing, Southampton, UK, 1st edition, 2003.

[3] R. Fernando, Fuels for Biomass Co-Firing, IEA Coal Research, London, UK, 2005.

[4] C. D. Di Blasi, G. Signorelli, and G. Portoricco, "Countercurrent fixed-bed gasification of biomass at laboratory scale," Industrial and Engineering Chemistry Research, vol. 38, no. 7, pp. 25712581, 1999.

[5] G. Gordillo, K. Annamalai, and N. Carlin, "Adiabatic fixed-bed gasification of coal, dairy biomass, and feedlot biomass using an air-steam mixture as an oxidizing agent," Renewable Energy, vol. 34, no. 12, pp. 2789-2797, 2009.

[6] D. L. Klass, Biomass for Renewable Energy, Fuels, and Chemicals, Academic Press, San Diego, Calif, USA, 1998.

[7] America's Energy Future Panel on Alternative Transportation Fuels, Liquid Transportation Fuels from Coal and Biomass: Technological Status, Costs, and Environmental Impacts, The National Academic Press, Washington, DC, USA, 2009.

[8] M. J. Prins, K. J. Ptasinski, and F. J. J. G. Janssen, "From coal to biomass gasification: comparison of thermodynamic efficiency," Energy, vol. 32, no. 7, pp. 1248-1259, 2007.

[9] R. Fernando, "Co-gasification and indirect co-firing of coal and biomass," in Profiles, pp. 9-14, IEA Clean Coal Centre, 2009.

[10] A. K. Sadhukhan, P. Gupta, T. Goyal, and R. K. Saha, "Modelling of pyrolysis of coal-biomass blends using thermogravimetric analysis," Bioresource Technology, vol. 99, no. 17, pp. 8022-8026, 2008.

[11] J. Bu, Kinetic Analysis of Coal and Biomass Co-Gasification with Carbon Dioxide, West Virginia University, 2009.

[12] C. Higman and M. van der Burgt, Gasification, Elsevier, New York, NY, USA, 2008.

[13] K. Liu, C. Song, and V. Subramani, Hydrogen and Syngas Production and Purification Technologies, John Wiley \& Sons, New York, NY, USA, 2010.

[14] S. Dutta, C. Y. Wen, and R. J. Belt, "Reactivity of coal and char. 1. In carbon dioxide atmosphere," Industrial and Engineering Chemistry Process Design and Development, vol. 16, no. 1, pp. 2030, 1977.

[15] E. Sima-Ella, G. Yuan, and T. Mays, "A simple kinetic analysis to determine the intrinsic reactivity of coal chars," Fuel, vol. 84, no. 14-15, pp. 1920-1925, 2005.

[16] C. Di Blasi, "Modeling chemical and physical processes of wood and biomass pyrolysis," Progress in Energy and Combustion Science, vol. 34, no. 1, pp. 47-90, 2008.

[17] A. K. Sadhukhan, P. Gupta, and R. K. Saha, "Modelling and experimental studies on pyrolysis of biomass particles," Journal of Analytical and Applied Pyrolysis, vol. 81, no. 2, pp. 183-192, 2008.

[18] J. Cai, Y. Wang, L. Zhou, and Q. Huang, “Thermogravimetric analysis and kinetics of coal/plastic blends during co-pyrolysis in nitrogen atmosphere," Fuel Processing Technology, vol. 89, no. 1, pp. 21-27, 2008.

[19] P. Ahuja, S. Kumar, and P. C. Singh, "A model for primary and heterogeneous secondary reactions of wood pyrolysis," Chemical Engineering and Technology, vol. 19, no. 3, pp. 272-282, 1996.

[20] A. W. Coats and J. P. Redfern, "Kinetic parameters from thermogravimetric data," Nature, vol. 201, no. 4914, pp. 68-69, 1964.

[21] W. de Jong, G. Di Nola, B. C. H. Venneker, H. Spliethoff, and M. A. Wójtowicz, "TG-FTIR pyrolysis of coal and secondary biomass fuels: determination of pyrolysis kinetic parameters for main species and NOx precursors," Fuel, vol. 86, no. 15, pp. 2367-2376, 2007.

[22] C. A. Koufopanos, N. Papayannakos, G. Maschio, and A. Lucchesi, "Modelling of the pyrolysis of biomass particles. Studies on kinetics, thermal and heat transfer effects," Canadian Journal of Chemical Engineering, vol. 69, no. 4, pp. 907-915, 1991.

[23] L. Zhou, Y. Wang, Q. Huang, and J. Cai, “Thermogravimetric characteristics and kinetic of plastic and biomass blends copyrolysis," Fuel Processing Technology, vol. 87, no. 11, pp. 963969, 2006.

[24] T. Hatakeyama and F. X. Quinn, Thermal AnalysisFundamentals and Applications to Polymer Science, John Wiley \& Sons, Chichester, UK, 1999.

[25] H. E. Kissinger, "Reaction kinetics in differential thermal analysis," Analytical Chemistry, vol. 29, no. 11, pp. 1702-1706, 1957.

[26] E. S. Freeman and B. Carroll, "The application of thermoanalytical techniques to reaction kinetics. The thermogravimetric evaluation of the kinetics of the decomposition of calcium oxalate monohydrate," Journal of Physical Chemistry, vol. 62, no. 4, pp. 394-397, 1958.

[27] A. Jerez, "A modification to the Freeman and Carroll method for the analysis of the kinetics of non-isothermal processes," Journal of Thermal Analysis, vol. 26, no. 2, pp. 315-318, 1983.

[28] J. Fermoso, B. Arias, M. V. Gil et al., "Co-gasification of different rank coals with biomass and petroleum coke in a high-pressure reactor for $\mathrm{H}_{2}$-rich gas production," Bioresource Technology, vol. 101, no. 9, pp. 3230-3235, 2010. 
[29] S. Gopalakrishnan and R. Sujatha, "Comparative thermoanalytical studies of polyurethanes using Coats-Redfern, Broido and Horowitz-Metzger methods," Der Chemica Sinica, vol. 2, no. 5, pp. 103-117, 2011.

[30] S. Syed, R. Qudaih, I. Talab, and I. Janajreh, "Kinetics of pyrolysis and combustion of oil shale sample from thermogravimetric data," Fuel, vol. 90, no. 4, pp. 1631-1637, 2011.

[31] "Introduction Department of Energy Coal Sample Bank \& Database," http://www.energy.psu.edu/copl/doesb.html.

[32] ASTM Standard D7582-12, Standard Test Methods for Proximate Analysis of Coal and Coke by Macro Thermogravimetric Analysis, ASTM International, West Conshohocken, Pa, USA, 2013.

[33] ASTM Standard D5373-08, Standard Test Methods for Determination of Carbon, Hydrogen and Nitrogen in Analysis Samples of Coal and Carbon in Analysis Samples of Coal and Coke, ASTM International, West Conshohocken, Pa, USA, 2013.

[34] ASTM Standard D4239-12, Standard Test Method for Sulfur in the Analysis Sample of Coal and Coke Using High-Temperature Tube Furnace Combustion, ASTM International, West Conshohocken, Pa, USA, 2013.

[35] S. S. Idris, N. A. Rahman, K. Ismail, A. B. Alias, Z. A. Rashid, and M. J. Aris, "Investigation on thermochemical behaviour of low rank Malaysian coal, oil palm biomass and their blends during pyrolysis via thermogravimetric analysis (TGA)," Bioresource Technology, vol. 101, no. 12, pp. 4584-4592, 2010.

[36] Y. Sun, A. Mukherjee, O. Kuznetsov, R. Thaner, L. B. Alemany, and W. E. Billups, "Functionalization by reductive alkylation and mapping of a subbituminous coal by energy dispersive $\mathrm{X}$ ray spectroscopy," Energy and Fuels, vol. 25, no. 4, pp. 1571-1577, 2011.

[37] M. Jeguirim and G. Trouvé, "Pyrolysis characteristics and kinetics of Arundo donax using thermogravimetric analysis," Bioresource Technology, vol. 100, no. 17, pp. 4026-4031, 2009.

[38] H. B. Vuthaluru, "Investigations into the pyrolytic behaviour of coal/biomass blends using thermogravimetric analysis," Bioresource Technology, vol. 92, no. 2, pp. 187-195, 2004.

[39] A. O. Aboyade, J. F. Görgens, M. Carrier, E. L. Meyer, and J. H. Knoetze, "Thermogravimetric study of the pyrolysis characteristics and kinetics of coal blends with corn and sugarcane residues," Fuel Processing Technology, vol. 106, pp. 310-320, 2013.

[40] E. Biagini, F. Lippi, L. Petarca, and L. Tognotti, “Devolatilization rate of biomasses and coal-biomass blends: an experimental investigation," Fuel, vol. 81, no. 8, pp. 1041-1050, 2002.

[41] S. Yaman and H. Haykiri-Acma, "Synergy in devolatilization characteristics of lignite and hazelnut shell during co-pyrolysis," Fuel, vol. 86, no. 3, pp. 373-380, 2007.

[42] S. Yaman and H. Haykiri-Acma, "Interaction between biomass and different rank coals during co-pyrolysis," Renewable Energy, vol. 35, no. 1, pp. 288-292, 2010.

[43] C. Meesri and B. Moghtaderi, "Lack of synergetic effects in the pyrolytic characteristics of woody biomass/coal blends under low and high heating rate regimes," Biomass and Bioenergy, vol. 23, no. 1, pp. 55-66, 2002. 


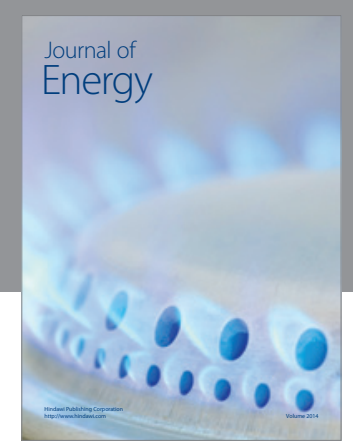

Journal of

Industrial Engineering
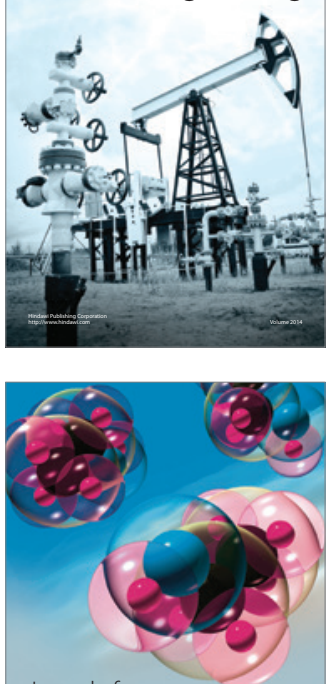

Fuels
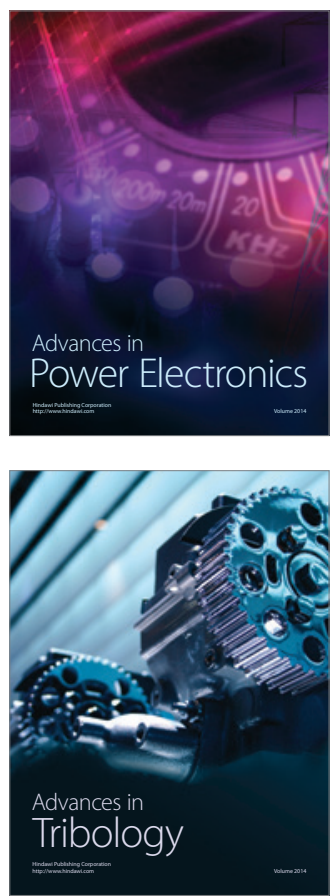

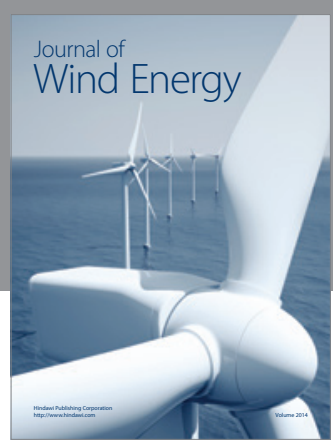

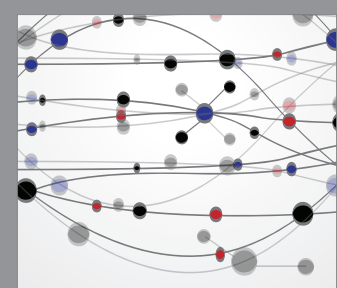

The Scientific World Journal

Submit your manuscripts at http://www.hindawi.com

Journal of

Structures
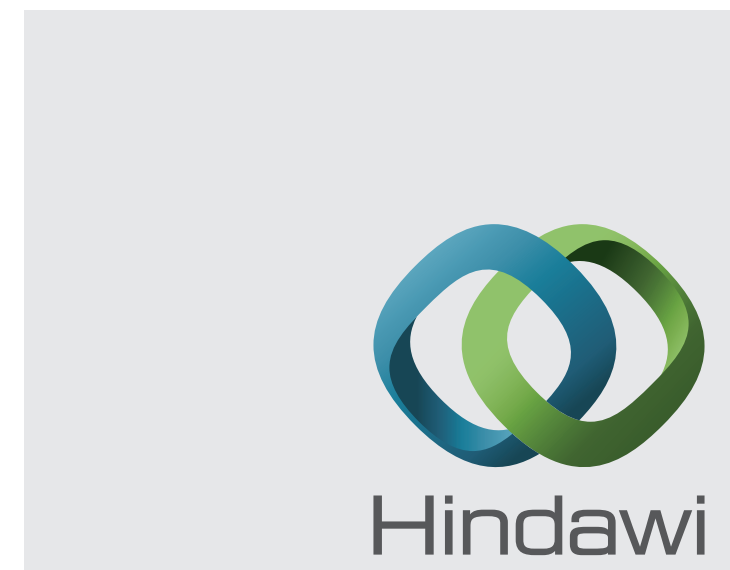

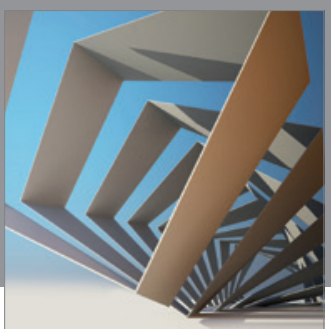

Rotating

Machinery
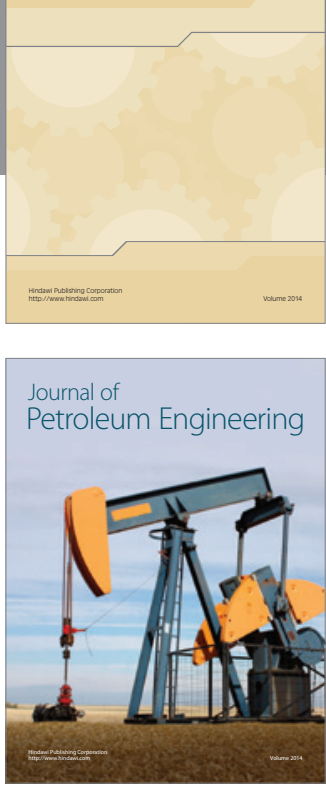

Journal of

Solar Energy
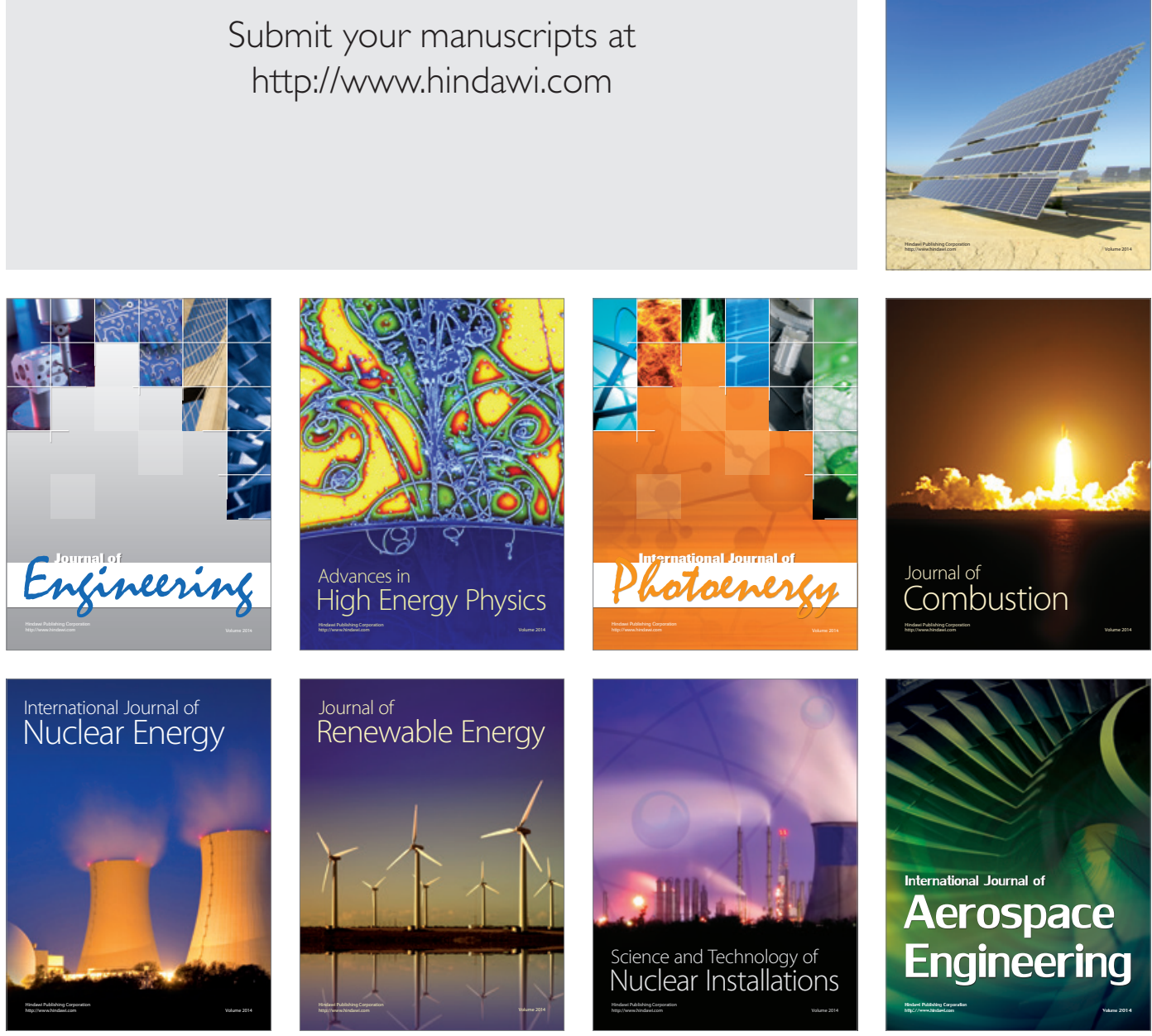